Supporting Information

Modulating Polarization of Perovskite-Based Heterostructures via in

Situ Semiconductor Generation and Enzyme Catalysis for Signal-

Switchable Photoelectrochemical Biosensing

Hao Yang, Min Zhang, Lei Wang, Renzhong Yu, Wenwen Tu, Zhaoyin Wang,* Rui

Wang, Huan Gao, and Zhihui Dai*

Jiangsu Collaborative Innovation Center of Biomedical Functional Materials and Jiangsu Key Laboratory of Biofunctional Materials, School of Chemistry and Materials Science, Nanjing Normal University, Nanjing, 210023, P. R. China. *Tel./Fax: +86-2585891051.

*E-mail: inzo@163.com (Z. Wang); daizhihuii@njnu.edu.cn (Z. Dai).

\title{
Table of Content:
}

1. TEM image of $\mathrm{Cs}_{3} \mathrm{Bi}_{2} \mathrm{Br}_{9}$ QDs (Figure $\mathrm{S} 1$ ).

2. Diameter distribution of $\mathrm{Cs}_{3} \mathrm{Bi}_{2} \mathrm{Br}_{9}$ QDs (Figure $\mathrm{S} 2$ ).

3. Band potential measurements of $\mathrm{Cs}_{3} \mathrm{Bi}_{2} \mathrm{Br}_{9}$ QDs (Figure S3).

4. Band potential measurements of $\mathrm{BiOBr}$ (Figure S4).

5. Photoelectric responses of $\mathrm{Cs}_{3} \mathrm{Bi}_{2} \mathrm{Br}_{9}$ QDs, $\mathrm{BiOBr}, \mathrm{Cs}_{3} \mathrm{Bi}_{2} \mathrm{Br}_{9}$ QDs/BiOBr heterostructure, and AAP (Figure S5).

6. Effect of AAP on photocurrent responses of $\mathrm{Cs}_{3} \mathrm{Bi}_{2} \mathrm{Br}_{9} \mathrm{QDs} / \mathrm{BiOBr}$ heterostructure (Figure S6).

7. ESR measurements of $\mathrm{Cs}_{3} \mathrm{Bi}_{2} \mathrm{Br}_{9} \mathrm{QDs} / \mathrm{BiOBr} / \mathrm{BiPO}_{4}$ in the absence or presence of AA (Figure S7).

8. Band potential measurements of $\mathrm{BiPO}_{4}$ (Figure S8).

9. Optimization of detection conditions (Figure S9). 
1. TEM image of $\mathrm{Cs}_{3} \mathrm{Bi}_{2} \mathrm{Br}_{9}$ QDs.

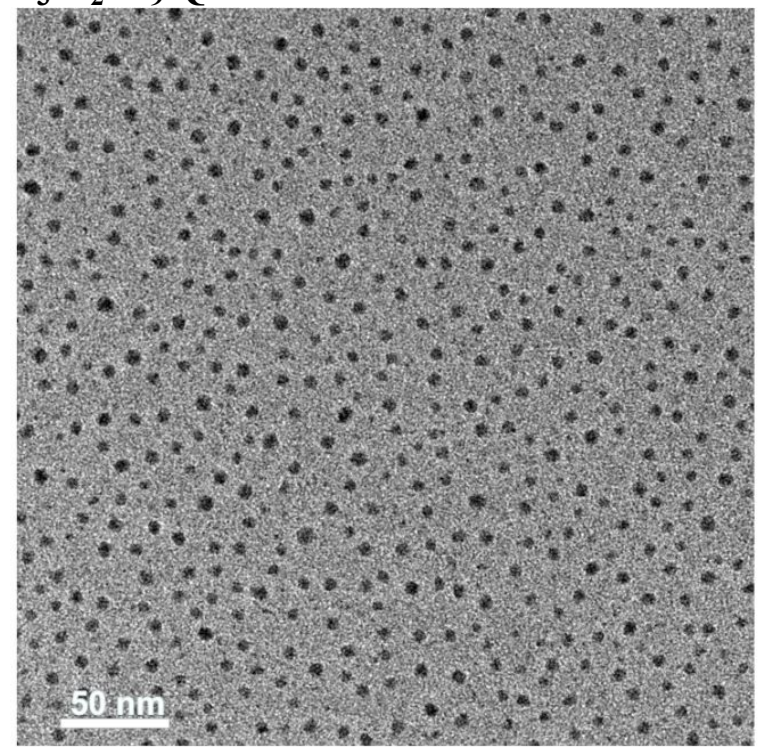

Figure S1. TEM image of $\mathrm{Cs}_{3} \mathrm{Bi}_{2} \mathrm{Br}_{9}$ QDs. 
2. Diameter distribution of $\mathrm{Cs}_{3} \mathrm{Bi}_{2} \mathrm{Br}_{9}$ QDs.

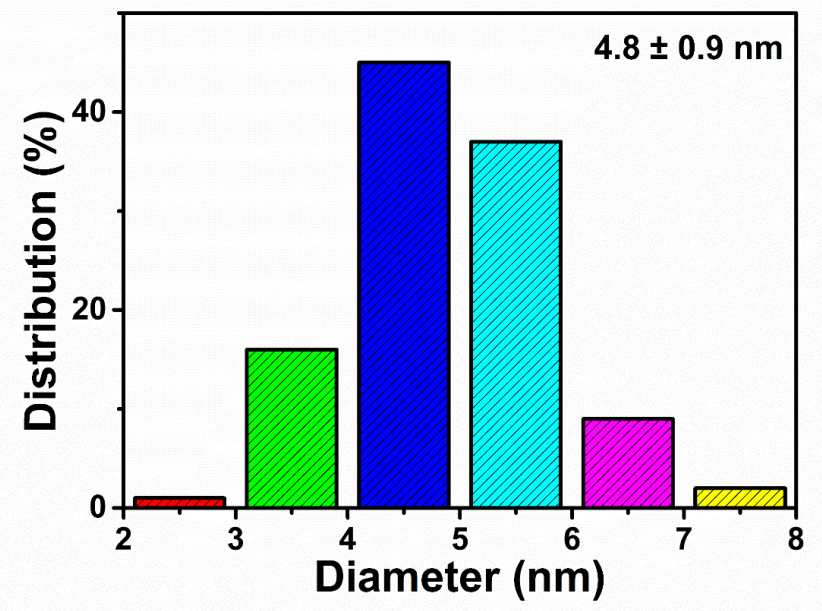

Figure S2. Hydrodynamic diameter distribution of $\mathrm{Cs}_{3} \mathrm{Bi}_{2} \mathrm{Br}_{9}$ QDs. 
3. Band potential measurements of $\mathrm{Cs}_{3} \mathrm{Bi}_{2} \mathrm{Br}_{9} \mathrm{QDs}$.
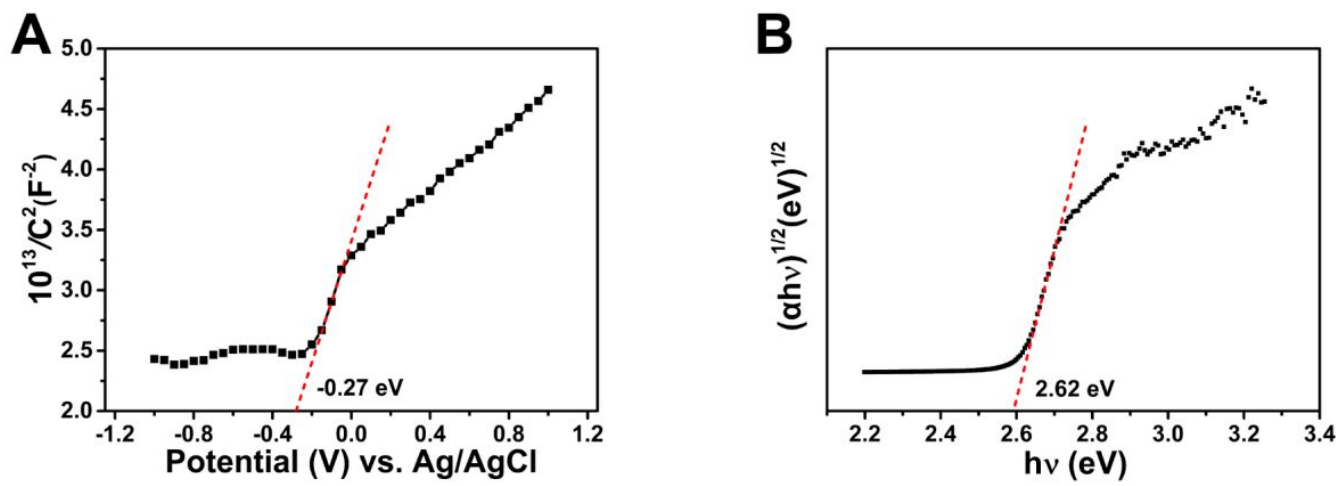

Figure S3. (A) Mott-Schottky curve and (B) Tauc plot of $\mathrm{Cs}_{3} \mathrm{Bi}_{2} \mathrm{Br}_{9}$ QDs. 
4. Band potential measurements of $\mathrm{BiOBr}$.
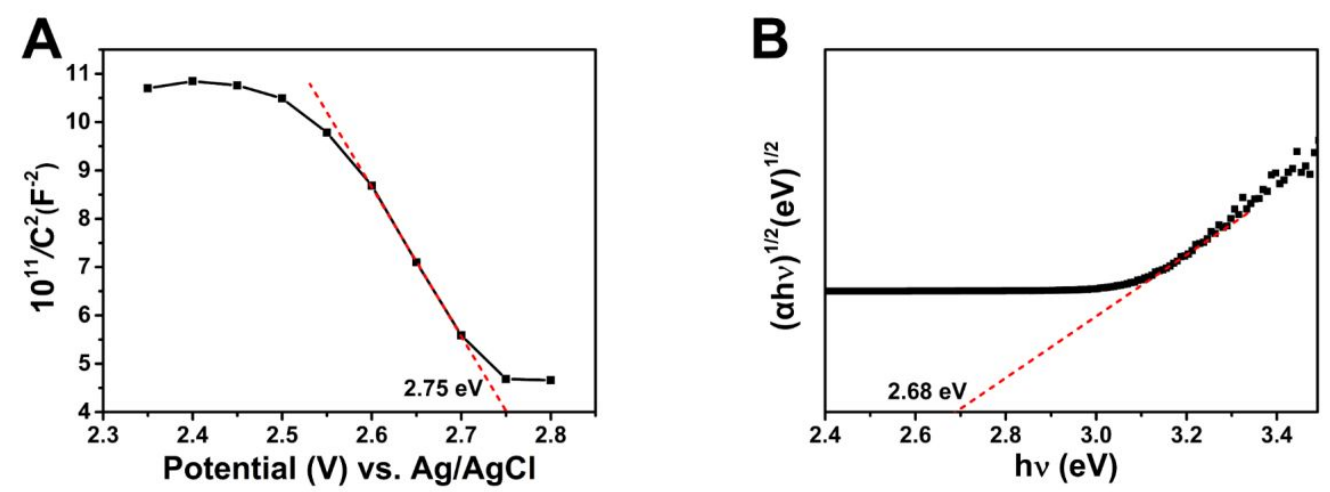

Figure S4. (A) Mott-Schottky curve and (B) Tauc plot of BiOBr. 
5. Photoelectric responses of $\mathrm{Cs}_{3} \mathrm{Bi}_{2} \mathrm{Br}_{9} \mathrm{QDs}, \mathrm{BiOBr}, \mathrm{Cs}_{3} \mathrm{Bi}_{2} \mathrm{Br}_{9} \mathrm{QDs} / \mathrm{BiOBr}$ heterostructure, and AAP.
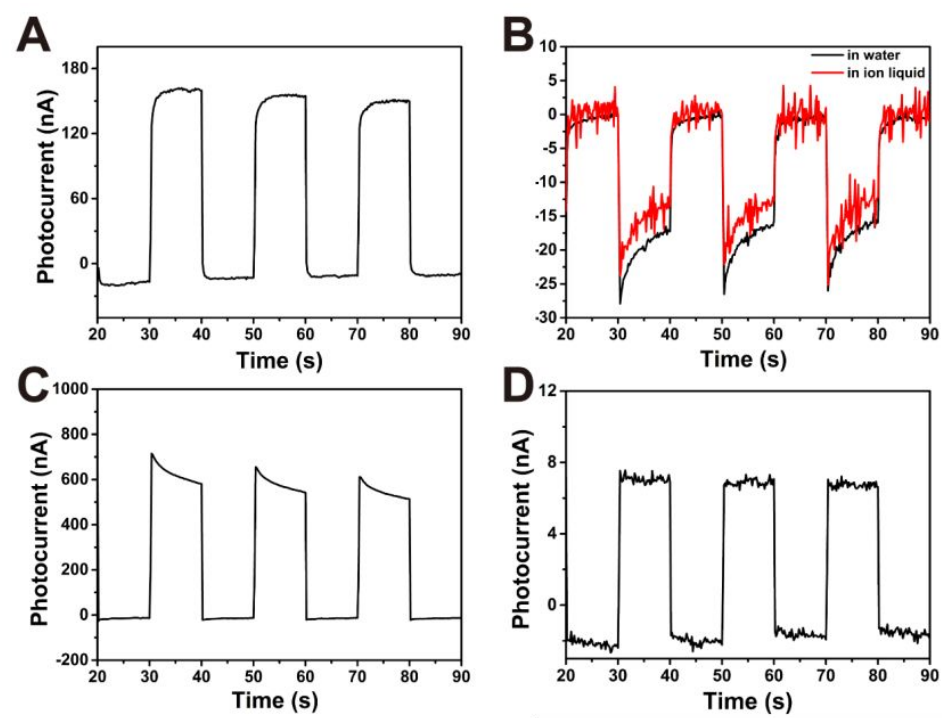

Figure S5. (A) Photocurrent response of $\mathrm{Cs}_{3} \mathrm{Bi}_{2} \mathrm{Br}_{9}$ QDs in ion liquid. (B) Photocurrent responses of $\mathrm{BiOBr}$ in (a) water and (b) ion liquid. (C) Photocurrent response of $\mathrm{Cs}_{3} \mathrm{Bi}_{2} \mathrm{Br}_{9} \mathrm{QDs} / \mathrm{BiOBr}$ heterostructure in ion liquid. (D) Photocurrent response of AAP in water. The concentration of $\mathrm{Cs}_{3} \mathrm{Bi}_{2} \mathrm{Br}_{9} \mathrm{QDs}, \mathrm{BiOBr}, \mathrm{Cs}_{3} \mathrm{Bi}_{2} \mathrm{Br}_{9} \mathrm{QDs} / \mathrm{BiOBr}$ heterostructure, and AAP is $2 \mathrm{mg} / \mathrm{mL}$. 
6. Effect of $\mathrm{AAP}$ on photocurrent responses of $\mathrm{Cs}_{3} \mathrm{Bi}_{2} \mathrm{Br}_{9}$ QDs/BiOBr heterostructure.

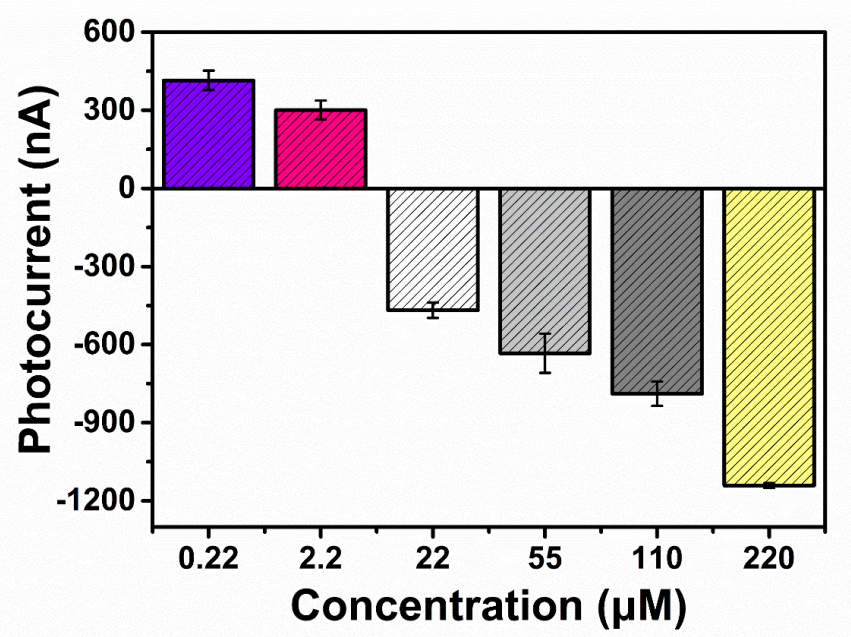

Figure S6. Photocurrent responses of $\mathrm{Cs}_{3} \mathrm{Bi}_{2} \mathrm{Br}_{9} \mathrm{QDs} / \mathrm{BiOBr}$ heterostructure with different concentrations of AAP. 
7. ESR measurements of $\mathrm{Cs}_{3} \mathrm{Bi}_{2} \mathrm{Br}_{9} \mathrm{QDs} / \mathrm{BiOBr} / \mathrm{BiPO}_{4}$ in the absence or presence of AA.
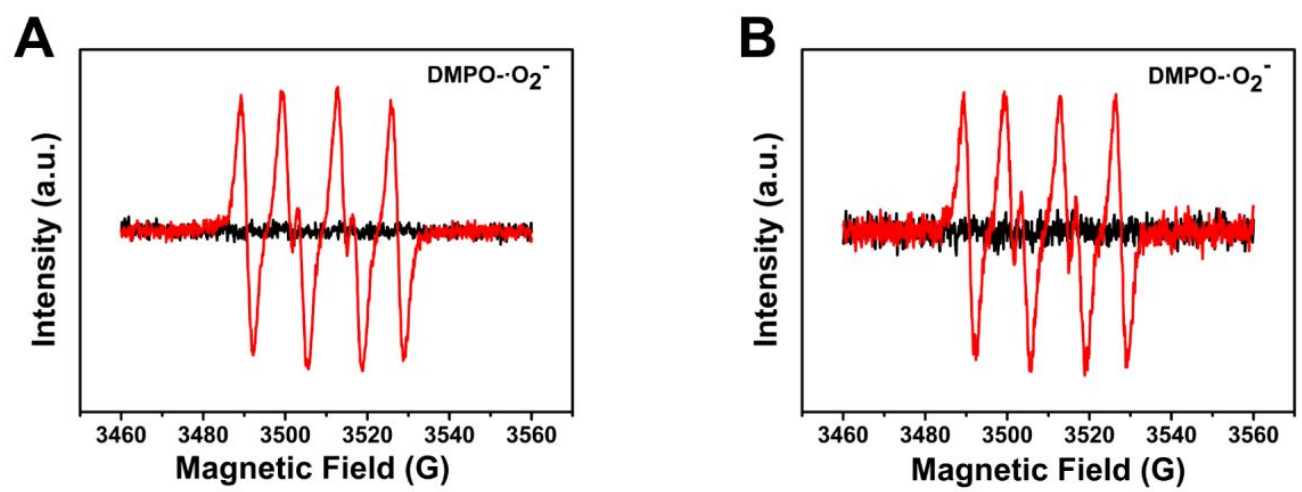

Figure S7. (A) ESR curves of $\mathrm{Cs}_{3} \mathrm{Bi}_{2} \mathrm{Br}_{9}$ QDs/ $\mathrm{BiOBr}$ heterostructure and AAP under dark or light conditions. (B) ESR curves of $\mathrm{Cs}_{3} \mathrm{Bi}_{2} \mathrm{Br}_{9} \mathrm{QDs} / \mathrm{BiOBr}$ heterostructure and ALP-treated AAP under dark or light conditions. 
8. Band potential measurements of $\mathrm{BiPO}_{4}$.

A

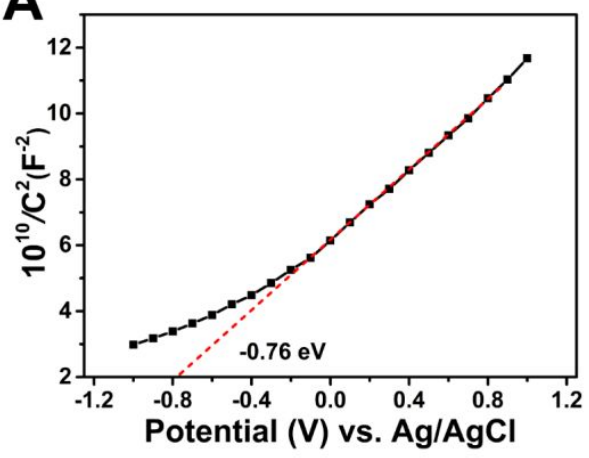

B

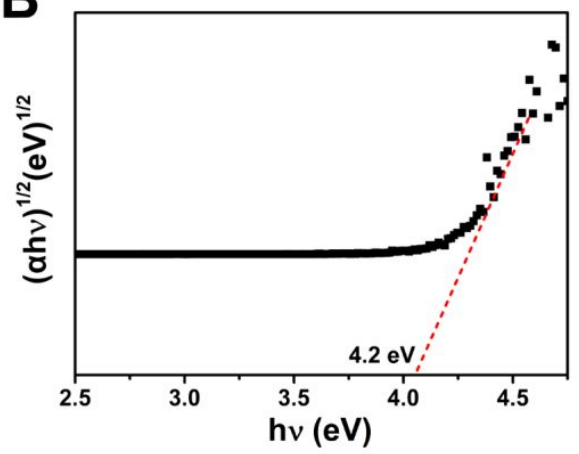

Figure S8. (A) Mott-Schottky curve and (B) Tauc plot of $\mathrm{BiPO}_{4}$. 
9. Optimization of detection conditions.
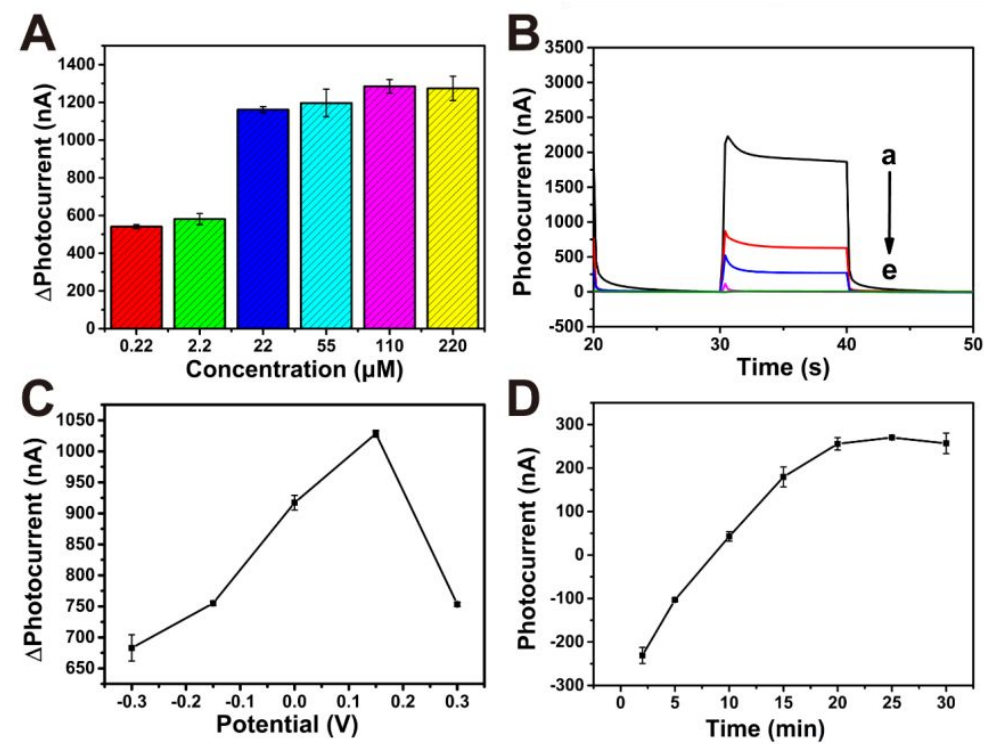

Figure S9. (A) Difference in photocurrent responses of $\mathrm{Cs}_{3} \mathrm{Bi}_{2} \mathrm{Br}_{9}$ QDs/BiOBr heterostructure with AAP and ALP-treated AAP. Concentrations of AAP are 0.22, 2.2, $22,55,110$ and $220 \mu \mathrm{M}$ respectively, and concentration of ALP in these assays is 10000 U/L. (B) The photocurrent responses of $\mathrm{Cs}_{3} \mathrm{Bi}_{2} \mathrm{Br}_{9}$ QDs/BiOBr heterostructure under the irradiation of different light sources. From a to e, the wavelengths of light are 365, 385, 405, 430 and $450 \mathrm{~nm}$ respectively. (C) Difference in photocurrent responses of $\mathrm{Cs}_{3} \mathrm{Bi}_{2} \mathrm{Br}_{9}$ QDs/BiOBr heterostructure with AAP and ALP-treated AAP at different applied potentials. (D) The photocurrent responses of $\mathrm{Cs}_{3} \mathrm{Bi}_{2} \mathrm{Br}_{9}$ QDs/ $\mathrm{BiOBr}$ heterostructure and ALP-treated AAP with different incubation time. The concentrations of ALP and AAP are $100 \mathrm{U} / \mathrm{L}$ and $22 \mu \mathrm{M}$ respectively. 